\title{
Serous cystadenoma with co-existing stromal tumor with sex-cord stromal elements: An extremely rare tumor
}

\author{
Asavari A. Bachhav
}

Civil Hospital, Nasik, India

Email: asavari.b@gmail.com

Received 2 September 2013; revised 2 October 2013; accepted 10 October 2013

Copyright (c) 2014 Asavari A. Bachhav. This is an open access article distributed under the Creative Commons Attribution License, which permits unrestricted use, distribution, and reproduction in any medium, provided the original work is properly cited. In accordance of the Creative Commons Attribution License all Copyrights (C) 2014 are reserved for SCIRP and the owner of the intellectual property Asavari A. Bachhav. All Copyright (C) 2014 are guarded by law and by SCIRP as a guardian.

\section{ABSTRACT}

Surface epithelial-stromal tumors are the most common neoplasm of ovary in the reproductive age and beyond. Less than $1 \%$ of epithelial ovarian tumors occur before the age of 21 years while $75 \%$ of sexcord stromal tumors (Sertoli and Leydig Cell) occur in the third and fourth decades of life. Serous tumors rarely occur in combination with germ cell tumors, sex-cord stromal tumors or granulosa cell tumors. Thus it is extremely rare for a combination of the above two tumors to occur before 21 years although a case report for a tumor with epithelial, stromal and sex-cord stromal elements for a 58-year-old patient has been documented. We believe ours is the first case in literature of a massive Serous Cystadenoma with co-existing stromal tumor with minor sex-cord stromal (Sertoli-Leydig Cell) elements.

\section{KEYWORDS}

\section{Cystadenoma; Stromal Tumor; Sex-Cord Elements}

\section{INTRODUCTION}

An ovarian epithelial tumor with co-existing stromal tumor with minor sex-cord stromal (Sertoli-Leydig Cell) elements is an extremely rare tumor. Serous tumors rarely occur in combination with germ cell tumors, sex-cord stromal tumors or granulosa cell tumors [1] although there have been several cases of stromal tumors with minor sex-cord elements reported in literature [2]. There is only one case has been reported so far of a mucinous ovarian tumor coexisting with stromal tumor with sex cord elements in a 58-year-old female [3]. It is extremely rare for a combination of the above two tumors to occur before 21 years and our case is the only case of this combination has been reported in literature so far.

\section{CASE REPORT}

An 18-year-old unmarried girl was admitted to our hospital with the chief complaints of pain and heaviness in abdomen.

\subsection{Menstrual History}

She had attained menarche at the age of 13 years and had regular cycles with moderate flow and mild dysmenorrhoea for which she did not require medications.

\subsection{Past History}

There was no significant past medical or family history.

\subsection{On General Examination}

Patient was conscious, well oriented in time, place and person. Mild pallor was present. There was no cyanosis, jaundice, clubbing or lymphadenopathy. There was no evidence of virilization.

\subsection{On Systemic Examination}

RS and CVS were normal.

\subsection{On Abdominal Examination}

A mass was felt extending from the hypogastric region to the lower border of the epigastric region and filling up the abdominal cavity. It was $35 \mathrm{~cm} \times 20 \mathrm{~cm}$ in size, cystic in consistency and not mobile. There was no tenderness, guarding or rigidity on palpation. Ascites was absent. Bowel sounds were present.

As patient was unmarried PV examination was not done. On PR examination the abdominal findings were confirmed. The fat planes of the rectum were intact and no mass or nodules were felt. There was no bleeding PR. 


\subsection{Investigations}

USG: A large, cystic lesion $30 \times 22 \times 15 \mathrm{~cm}$ arising from pelvis extending upto epigastric region. Solid component, internal echoes and internal septations seen. No calcifications or ascites.

\subsection{CT Scan}

Hypodense lesion $35 \times 22 \times 15 \mathrm{~cm}$. Rest of the findings were similar to USG. No lymphadenopathy. Liver, spleen, kidney were normal.

\subsection{Hematology}

Serum CA-125: $24.1 \mathrm{U} / \mathrm{L}($ Normal 0 - $35 \mathrm{U} / \mathrm{L})$;

Serum BETA-HCG: <1.20 mIU/L;

Serum AFP: $72.13 \mathrm{ng} / \mathrm{ml}$ (Normal $<8.5 \mathrm{ng} / \mathrm{ml}$ ).

Her hematocrit showed $\mathrm{aHb} \%$ of $8 \mathrm{gm} \%$ and the rest of the blood count was normal. Liver and Renal Function Tests were normal.

Based on the above investigations a diagnosis of ovarian neoplasm mostly of germ cell origin was made and the decision for a staging exploratory laparotomy was taken after blood transfusion for anemia.

\subsection{Intra-Operatively}

Right sided ovarian tumor present, approximately $40 \mathrm{~cm}$ $\times 20 \mathrm{~cm} \times 15 \mathrm{~cm}$ in size, cystic with septations with solid areas and extending upto the right hypochondrium (Figure 1). Her right fallopian tube was adherent to the mass and right ovary could not be made out separately. No enlarged lymph nodes or evidence of metastasis was present. No ascites present. Left ovary and tube were normal. Right oophorectomy and partial salpingectomy with prophylactic infra-colic omentectomy was done.

\subsection{On Cut-Section}

4 litres of clear and reddish fluid was drained from the tumor. Large ovarian mass measuring $26 \times 18 \times 9 \mathrm{~cm}$. Upto $60 \%$ cystic and $40 \%$ solid component. Cystic component is composed of multilocular cysts \& small grape-like cysts arising from the wall of larger cysts. Solid component is edematous \& variegated (Figure 2).

\subsection{Histopathological Report}

The tumor was having upto $60 \%$ cystic and $40 \%$ solid component. The cystic component was lined by flattened epithelium in majority of areas and very few areas showed low columnar cells with cilia. (Figure 3) The solid component was composed of ill-defined fascicles of elongated cells with moderate cytoplasm and elongated nuclei. These cells are intermixed with cells with moderate amount of eosinophilic cytoplasm and round nuclei

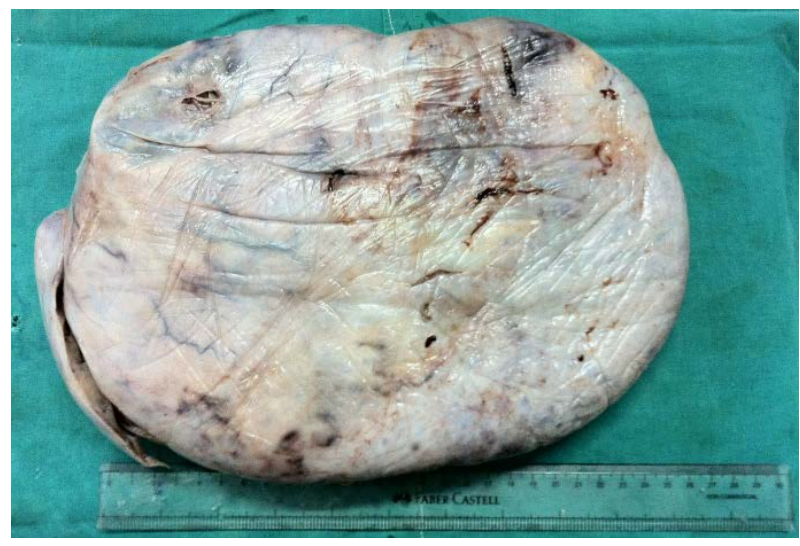

Figure 1. External surface of tumor after draining fluid.

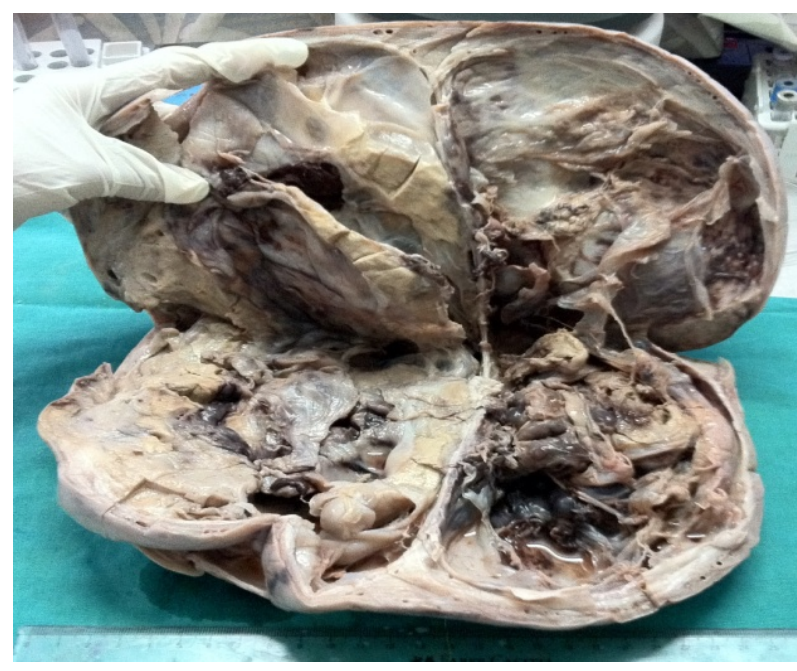

Figure 2. Cut surface of tumor.

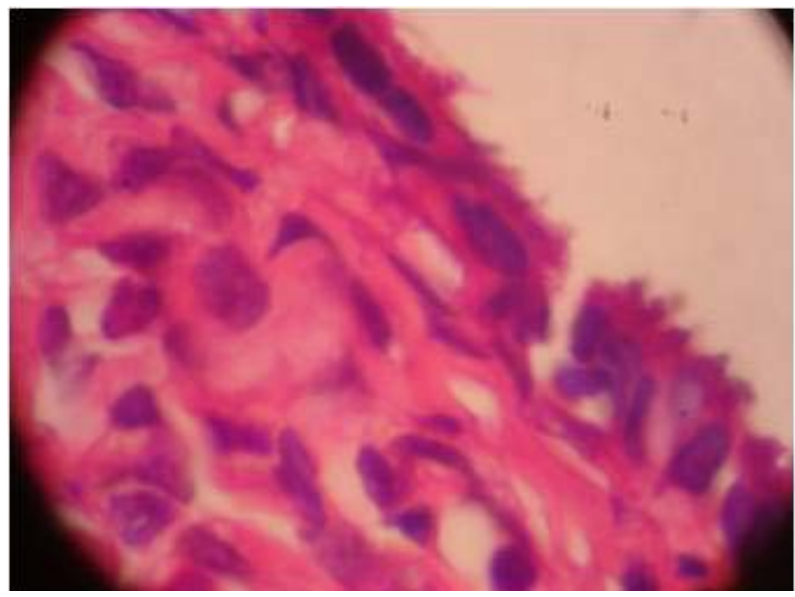

Figure 3. H \& E (40×) showing serous cystadenoma component.

(Luteinized cells). Also seen were few tubules lined by Sertoli cells (amounting to $<10 \%$ of tumor volume) (Figure 4). Mitosis was rarely seen.

Fallopian tube and omentum showed normal morphology. 


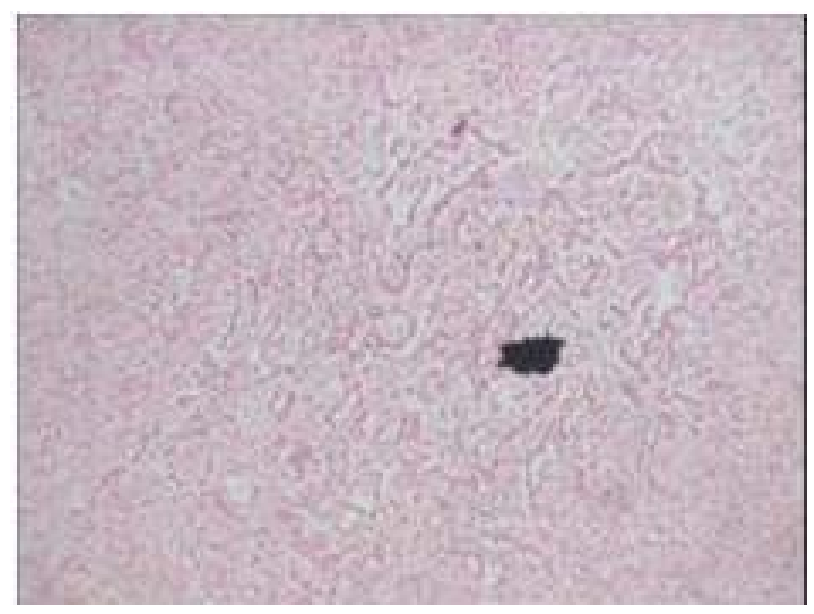

Figure 4. H \& E stain (4×) showing sex-cord component.

Immunohistochemistry was done to substantiate our diagnosis. Results were:

Pan cytokeratin: positive;

Inhibin: positive;

Calretinin: positive;

Alpha-fetoprotein: negative.

\section{DISCUSSION}

Surface epithelial-stromal tumours are the commonest of ovarian tumours. Sex cord stromal tumours are less common. Surface epithelial-stromal tumors account for approximately $60 \%$ of all ovarian tumors and approximately $90 \%$ of malignant ovarian tumors of which $75 \%$ are serous epithelial while sex cord-stromal tumors account for approximately $8 \%$ of all ovarian tumors and approximately $7 \%$ of all malignant ovarian tumors [4]. A combination of these tumours are very rarely encountered. The more common combinations of ovarian tumours encountered are with mucinous cystadenoma in which a combination of Brenner tumor, mature cystic teratoma, Sertoli-Leydig cell tumor, or even a serous cystadenoma may be seen [5].

The lining epithelium of the cyst wall was coinciding with that of a serous cystadenoma while the presence of luteinized cells and tubules lined by sertoli cells could either be a germ cell tumor or sertoli-leydig cell tumor. But immunohistochemistry was negative for alpha-fetoprotein and positive for inhibin and calretinin which is diagnostic for sertoli-leydig cell tumors [6,7]. Inhibin positivity is well documented in fibrothecomatous components of sex cord stromal tumors, but still the possibility of granulose cell tumor was ruled out by the absence of characteristic features such as Call-Exner body or nuclear grooves.

The serous element could be confused with a heterologous sex cord stromal tumor or a degenerating cystadenofibroma. But the lining epithelium was characteristic of serous cystadenoma (tubal) type and in a degenerating fibroma no lining epithelium would be seen in cyst wall [8].

Because of the presence of definite sex-cord elements and presence of a definitive lining epithelium for the cyst wall along with a demarcation between the stromal elements, we can conclude that the serous cystadenoma arose de-novo.

\section{CONCLUSION}

The patient had an uneventful post-operative period. As both the elements of the tumor were benign, patient was asked to follow-up in OPD and was uneventful till date of reporting. While this might be the first case of a huge serous cystadenoma coexisting with stromal tumor with minor sex cord-stromal elements to be reported in literature in a patient younger than 21 years, it was also important to keep in mind that surface-epithelial stromal tumors can also, albeit rarely present as a mixed tumor with multiple tissue elements. Ours is probably the only case report of such a combination in literature.

\section{REFERENCES}

[1] Russel, P. (1994) Surface epithelial stromal-tumors of the ovary. In: Kurman, R.J., Ed., Blaustein's Pathology of the Female Genital Tract, 4th Edition, Spinger-Verlag, New York, 724.

http://dx.doi.org/10.1007/978-1-4757-3889-6_18

[2] Young, R.H. and Scully, R.E. (1983) Ovarian stromal tumors with minor sex cord elements: A report of seven cases. The International Journal of Gynecological Pathology, 2, 227-234.

http://dx.doi.org/10.1097/00004347-198303000-00001

[3] Yang, S.W., Cho, M.Y., Jung, S.H., Lee, K.G., Cha, D.S. and Kim, K.R. (2001) Mucinous cystadenoma coexisting with stromal tumor with minor sex-cord elements of the ovary: A case report. Journal of Korean Medical Science, 16, 237-240.

[4] Young, R.H. (2011) Blaustein's pathology of the female genital tract. In: Kurman, R.J., Hedrick Ellenson, L. and Ronnett, B.M., Eds., 6th Edition, Springer, New York, 786.

[5] Fox, H. and Wells, M. (2003) Surface epithelial stromal tumors of the ovary. In: Fox, H. and Wells, M., Eds., Haines \& Taylor Obstetrical and Gynaecological Pathology, Vol. 1, Churchill Livingstone, Madrid.

[6] Kommoss, F., Oliva, E., Bhan, A.K., Young, R.H. and Scully, R.E. (1998) Inhibin expression in ovarian tumors and tumor-like lesions: An immunohistochemical study. Modern Pathology: An Official Journal of the United States and Canadian Academy of Pathology, 11, 656-664.

[7] Movahedi-Lankarani, S.M.D. and Kurman, R.J.M.D. (2002) Calretinin, a more sensitive but less specific marker than [alpha]-inhibin for ovarian sex cord-stromal neoplasms: An immunohistochemical study of 215 cases. American 
Journal of Surgical Pathology, 26, 1477-1483.

[8] Lee, K.R., Tavassoli, F.A., Prat, J., et al. Surface epithelial-stromal tumors. In: Tavassoli, F.A. and Devilee, P.,
Eds., Pathology \& Genetics of Tumors of the Breast and Female Genital Organs, IARC Press, Lyon, 124. 